\title{
All about Nystagmus
}

\section{Partha Haradhan Chowdhury ${ }^{*}$, Brinda Haren Shah ${ }^{2}$ and Nripesh}

\section{Tiwari ${ }^{3}$}

1M.Optom, Associate Professor, Principal, Department of Optometry, Shree Satchandi Jankalyan Samiti Netra Prasikshan Sansthan, Pauri, Affiliated to Uttarakhand State

\section{Short Communication}

Volume 3 Special Issue 1

Received Date: September 17, 2018

Published Date: October 04, 2018

Medical Faculty, Dehradun, India

2M.Optom, Guest Lecturer, Department of Optometry, Shree Satchandi Jankalyan Samiti Netra Prasikshan Sansthan, Pauri, Affiliated to Uttarakhand State Medical Faculty, Dehradun, India

${ }^{3}$ D.Optom, General Secretary and Chief Optometrist, Department of Optometry, Shree Satchandi Jankalyan Samiti Netra Prasikshan Sansthan, Pauri, Affiliated to Uttarakhand State Medical Faculty, Dehradun, India

*Corresponding author: Partha Haradhan Chowdhury, M. Optom, Associate Professor, Principal, Department of Optometry, Shree Satchandi Jankalyan Samiti Netra Prasikshan Sansthan, Pauri, Affiliated to Uttarakhand State Medical Faculty, Dehradun, India, Email: optometrypublish@gmail.com

\section{Abstract}

This paper describes about nystagmus, its etiology, clinical features, evaluation and treatment.

Keywords: Nystagmus; Spasmus Nutans

\section{Introduction}

It is an involuntary, to and fro eye movement. It may be associated with deterioration of visual acuity or it may present with visual acuity up to 6/9 also. Usually, in case of nystagmus, fixation is unstable as Fixation stability is dependent on Persuites, optokinetic and vestibular system $[1,2]$.

\section{Etiology}

- Unknown usually

- Mainly due to genetics and developmental anomalies during critical and plasticity period.

- Pathology in afferent pathway

- Disorder in occulomotor control

- $13 \%$ case may be responsible for cerebral palsy

\section{Characteristics}

\section{A. Amplitude}

It means how much eye is fixational unstable from the fixation point

Small $<2$ degrees

Moderate 2 degree to 9 degree

Large $>10$ degree

Amplitude of Nystagmus is measured by the millimeter ruler.

\section{B. Direction}

Direction of the Nystagmus should be checked once it is diagnosed. It can be Horizontal, Vertical, Torsional or combined.

C. Type

It can be Jerky, Pendular or Mixed 


\section{Open Access Journal of Ophthalmology}

\section{Frequency}

It shows how frequent nystagmus occurs.

If nystagmus is slow, then it will be $<0.5 \mathrm{~Hz}$

If Nystagmus is moderate, then it will be 0.5 to $2 \mathrm{~Hz}$

If Nystagmus is fast, then it will be $>2 \mathrm{~Hz}$

\section{E. Constancy}

It means whether nystagmus is always present or not

\section{F. Symmetry}

Here, deviation or movement in all directions is same or not should be checked.

\section{G. Latency}

Nystagmus is present in one eyed patient or not.

\section{Clinical Evaluation}

"Spasmus Nutans" The meaning of Spasmus Nutans is whether nystagmus is constant or intermittent it should be seen that, it is associated with head nodding. During clinical evaluation, patient should be asked:

i. Onset: It means when nystagmus is seen since birth or before 6 months of age.

ii. Associated condition: Patient should be asked about any type of Neurological disorder, Trauma, Infection, Genetic Factor, Medications etc.

iii. Patient should be asked about Refractive error.

\section{Treatment}

To treat the Nystagmus properly, practioner should diagnose exact null point location. In case of Eso deviation, the null point will be at the nasal Retina and in case of Exo deviation; the null point will be at the Temporal Retina [3-5].

- First step should be full cycloplegic refraction

- Then, RGP contact lenses should be given, because her image clearance is better compared to soft contact lenses. When image will be sharper, nystagmus will be reduced.

- Anti Suppression Therapy

- For a transient period, pharmacological therapy is very essential. Clonazepam ( 1 to $2 \mathrm{mg}$ ) may act upto 72 hours for one dose

- In surgical therapy, primary position should be shifted to the null point

\section{References}

1 Kenneth W Wright, Peter H Spiegel (2003) Pediatric Ophthalmology and Strabis-mus. $2^{\text {nd }}($ Edn.).

2 Kenneth W Wright, Peter H Spiegel, Lisa Thompson (2006) Handbook of Pediatric Strabismus and Amblyopia.

3 Kenneth W Wright (2007) Color Atlas of Strabismus Surgery: Strategies and Techniques.

4 Theodore Grosvenor, Theodore P (2007) Primary Care Optometry. $5^{\text {th }}$ (Edn.).

5 Mitchell Scheiman, Bruce Wick (2008) Clinical Management of Binocular Vision. $3^{\text {rd }}$ (Edn.).

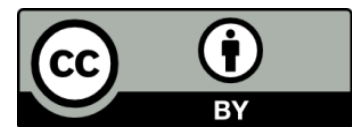

